\title{
Change is permanent: thoughts on the fading of cochineal-based watercolor pigments
}

\author{
Barbara H. Berrie ${ }^{1 *}$ and Yoonjoo Strumfels ${ }^{2}$
}

\begin{abstract}
Background: Color change in artworks has been commented on for centuries. Fading of watercolor pigments is a notable alteration. Pigments based on carminic acid are among those particularly prone to color loss, but the mechanism and factors are not well understood.

Results: We painted out three pigments prepared from the aqueous extract of carminic acid (CA) from Dactylopius coccus: the uncomplexed, and aluminium- and tin-complexed lakes. These were applied in a $2 \%$ gum Arabic solution to papers that were acidic, neutral or alkaline $\mathrm{pH}$ and exposed to accelerated light aging in a weatherometer. The comparative rate of fading was dependent on the complexation and on the $\mathrm{pH}$ of the substrate. On alkaline paper, the Al complex was least light stable, on neutral paper the three colorants responded similarly, and on acidic paper the tin complex was the least light stable. This is discussed in light of the published information on reactions and mechanism of color loss of CA.
\end{abstract}

Keywords: Carminic acid, Carmine, Cochineal, Lake pigments, Fading, Anthraquinone

\section{Background}

Color change in artworks has been commented on for centuries; today our awareness of its occurrence and our understanding of the complexity of the chemistry is increasing. Long ago, Cennino Cennini wrote in c. 1400 on the alteration of color, giving examples of inherent vice, problems due to incompatibility of materials, and the effects of methods of preparation of pigments causing color change in works of art. He noted that red lead and orpiment turn black in air; he provided a list of pigments that ought not be used in fresco, and he commented that red lakes are unstable, noting that the method used for preparation of the pigments has a large effect on the stability of the product: specifically, he said that the lake pigment made from cloth shearings does not last at all compared to that made directly from the resin, due to the presence of alum [1], an observation which will be discussed further.

\footnotetext{
*Correspondence: b-berrie@nga.gov

${ }^{1}$ Scientific Research Department, National Gallery of Art, 2000B South

Club Drive, Landover, MD 20785, USA

Full list of author information is available at the end of the article
}

There are multiple reasons to investigate the reactivity of artists' materials; for example, knowing what was used helps us appreciate the artistic intent, and understanding the chemistry of change allows acceptance of inevitable alteration, but also helps us to mitigate change due to factors we can control-such as storage and exhibition conditions, and adverse reactions to specific treatments. Although fading of fugitive colorants, for example, turnsole, eosine, or tartrazine, is notable and well known to conservators, other changes may be slow or be initiated by a specific chemical event, such as a change in water content or $\mathrm{pH}$, and therefore the cause is less immediately recognizable. Investigating and understanding immediate or incipient change requires research into the fast and slow chemical reactions of inorganic and organic compounds, their response to light, humidity and pollutants, crystallographic changes, and also into the interactions among the chemical constituents of paint. Without knowledge of the original pigment's color we cannot be sure if we are observing change, we are lacking information needed to understand the artist's original intent, and it is challenging to specify suitable display conditions and/or treatment options.

Recent studies have taken advantage of advanced instrumental methods to characterize the products of 
color change of artists' pigments and investigate their causes. The presence of pararealgar in paintings has been shown to be due to transformation of realgar on exposure to visible light [2], certain forms of lead chromate (apparently those prepared a specific way) are not stable in light and react with the binder, changing color and decreasing the strength of the paint film [3]. The complexity of factors involved in the color changes of inorganic pigments such as red lead [4, 5], cadmium yellow [6], and vermilion [7-9]-long observed-have been investigated. These pigments can be synthesized using different methods or have variations in their formulation that give products with different hues and significantly different reactivity. The reactions between pigments and binding media are becoming better understood: the example of metal soap formation, which changes the opacity of paint and therefore its effect on color is notable [10], the change in color of verdigris has been recorded [11-13].

Watercolor paintings are known to be particularly sensitive to light. In the late 1880 s a controversy over the fading of watercolors in English national collections prompted an enquiry and in 1888 the Russell and Abney report was presented to Parliament in response [14]. This was perhaps the first concerted effort to investigate the effect of environmental conditions on color change. Since then there have been numerous investigations on the instability of colorants tempered in aqueous binding media and their response to light and oxidants $[15,16]$. The red colors based on cochineal, that is carminic acid (CA), 7-D-glucopyranosyl-3,5,6,8-tetra- hydroxy-1-methyl-9,10-dioxo-anthracene-2-carboxylic acid (Fig. 1), a water-soluble extract from the insect Dactylopius coccus $[17,18]$ are among those that are highly light sensitive. In his 1662 translation of Antonio Neri's book on glass making, Christopher Merrett noted that, "The only inconvenience of Lakes made hence [from cochineal] would be, that they would soon Tarnish and lose their colour in the air, or with wet...by reason of the Salts relenting" [19]. The English chemist, A. H. Church said,<smiles>Cc1c(C(=O)O)c(O)cc2c1C(=O)c1c(O)c([C@@H]3O[C@H](CO)[C@@H](O)[C@H](O)[C@H]3O)c(O)c(O)c1C2=O</smiles>

Fig. 1 Structure of carminic acid, 7-D-glucopyranosyl-3,5,6,8-tetrahydroxy-1-methyl-9,10-dioxo-anthracene-2-carboxylic acid
"Beautiful and rich as are the colours prepared from cochineal, not one of them should ever find a place upon the palette of the artist. They all become brownish and ultimately almost disappear after a short exposure to sunlight or the more prolonged attack of strong diffused daylight" [20].

This paper presents results that test Cennini's observation on the relative reactivity of an alum-mordanted anthraquinone pigment (cochineal) compared to the uncomplexed compound, and examines the role of the $\mathrm{pH}$ of the paper substrate in the relative rate of fading of cochineal-based watercolor pigments made using three nineteenth-century recipes.

\section{Methods}

\section{Cochineal pigments}

Pigments were prepared based on recipes in a late nineteenth century book on pigment manufacture [21]. Dried cochineal insects (Colpa Apx Grupo Inca, Peru (batch SO181-13/01 21/12/2001)) as received were finely ground using a pigment mill to give a dark red powder that was used in all subsequent experiments. Water was purified using a Millipore RO system (18 $\mathrm{M} \Omega$ - $\mathrm{cm})$. Potassium bitartrate $\left(\mathrm{KC}_{4} \mathrm{H}_{5} \mathrm{O}_{6}\right.$, McCormicks $)$ and potassium aluminium sulphate (alum, $\mathrm{KAl}\left(\mathrm{SO}_{4}\right)_{2} \cdot 12 \mathrm{H}_{2} \mathrm{O}, 98 \%$, Aldrich Chemical Co.) were used as received. Tin(IV) chloride was prepared by dissolving tin (Sn, Analytical Reagent grade, Mallinckrodt) in $6 \mathrm{M}$ hydrochloric acid (Fisher Scientific). The resultant solution was decanted off excess metallic tin and left exposed to air for several days prior to use. All pigments were allowed to precipitate, then filtered, rinsed in a filter funnel, dried and then reground in water. Sefar Yellow Swiss Nitex mesh was used in the Buchner funnel and in lieu of paper filters which clogged easily.

\section{Unlaked carmine (CA)}

Powdered cochineal insects $(80 \mathrm{~g})$ were placed in a nylon bag and suspended in $500 \mathrm{~mL}$ water and boiled for $1 \mathrm{~h}$. The deeply colored aqueous extract was covered with Parafilm and allowed to sit for 2 days. Following this, $\mathrm{KC}_{4} \mathrm{H}_{5} \mathrm{O}_{6}$ $(2.5 \mathrm{~g})$ was added, stirred and solid pigment allowed to settle out over several days. The supernatant was decanted off and the pigment that had settled was allowed to dry, then washed in a filter funnel and reground in minimum water using a muller and again allowed to dry.

\section{Alum-laked pigment (CA-Al)}

The solid obtained above was dissolved in hot water and solid alum added. The mixture was allowed to cool and the aluminium complex precipitated. The supernatant was decanted off and the product allowed to dry then washed in a Buchner filter, then ground with water and allowed to dry. 


\section{Tin-laked pigment (CA-Sn)}

The tin lake was prepared analogously with tin chloride solution being added dropwise to the solution of carmine to give a bright red precipitate that was washed in a Buchner filter funnel, dried, reground in water and allowed to dry.

\section{Paper substrates}

Whatman qualitative filter paper No. 3 (c. $27 \mathrm{~cm}$ diameter) with no further treatment was used as a support with a near neutral $\mathrm{pH}$. For alkaline papers, either Whatman qualitative filter paper No. 3 was immersed in calcium hydroxide solution (pH c. 13) for $15 \mathrm{~min}$ and air dried, or commercially-obtained buffered acid-free tissue paper was used. For experiments involving unlaked carmine and tin-laked carmine only the tissue paper was used. An acidic paper was prepared by brushing Whatman qualitative filter paper No. 3 with a traditional gelatin/alum paper sizing solution prepared using a $2.5 \% \mathrm{w} / \mathrm{vol}$ aqueous solution of gelatin mixed with alum in 100:1 wt\% ratio $[22,23]$ and dried in air. The surface $\mathrm{pH}$ was measured using an Oakton Phelect flat electrode on the wetted surface of the papers to provide a general sense of the $\mathrm{pH}$.

\section{Paint}

Watercolor paints were made by mixing the dried and reground pigment into a $2 \% \mathrm{w} / \mathrm{vol}$ solution of gum Arabic. The paint was applied onto large sheets of the paper substrates (diameter c. $27 \mathrm{~cm}$ ) using a spray gun. A very dilute solution or suspension was used to avoid clogging the spray gun, and the color was built up using many sweeping passes, each with little pigment, until the maximum reflectance in the visible region was $34-45 \%$ following the ASTM 5067-93 method (Standard Specification for Artists' Watercolor Paints). The application was uniform, variations in measured color over the sheets were within $\pm 0.4 \Delta \mathrm{E}$ units.

\section{Color measurement}

Color was measured using a HunterLab UltraScan XE spectrophotometer in CIE L"a*b* space. Six measurements were made on each of the samples, which were prepared in duplicate. Color change, $\Delta \mathrm{E}$, was calculated according the equation:

$$
\Delta \mathrm{E}=\left(\left(\Delta \mathrm{L}^{*}\right)^{2}+\left(\Delta \mathrm{a}^{*}\right)^{2}+\left(\Delta \mathrm{b}^{*}\right)^{2}\right)^{0.5}
$$

In the samples not exposed to light, color change was calculated relative to the first measurement, and the average of five values was calculated. Color change in exposed samples was calculated with respect to the average measured $\mathrm{L}^{*} \mathrm{a} * \mathrm{~b} *$ of the unexposed swatches. The value of $\Delta \mathrm{E}$ in each set was almost always smaller than 1 , and the average of six measurements was less than 1 . Values from two replicates of each preparation were measured. The greatest variation was in the paint-outs of the tin-complexed samples, perhaps due to the grainier paint.

\section{Aging}

Samples were light-aged in an Atlas Ci65A weatherometer using simulated daylight through plate glass at $75,000 \mathrm{~lx}$ (the equivalent of a very bright sunny day). Paper swatches affixed to aluminum plates using metal clips were removed at time intervals ranging from 1 to $70 \mathrm{~h}$ (by which time one sample had bleached completely) and the color measured. Two swatches of each sample were used. Temperature and RH were not controlled.

\section{Results}

The watercolor paints on all papers changed color, some considerably, on being applied to the paper supports, suggesting that protonation and/or re-complexation occurred. The surface $\mathrm{pH}$ of the paper did not vary extremely, the neutral papers having $\mathrm{pH}$ around 5.7, close to that of $\mathrm{CO}_{2}$-saturated deionized water, while the acidified papers had a $\mathrm{pH}$ range $4.2-4.5$, and the $\mathrm{pH}$ of alkaline papers ranged 7.2-7.6. It is known that the alkaline reserve in papers is in fact different from surface measurement of $\mathrm{pH}$, which itself does not give values that relate directly to traditional measurements of the activity of protons in solution [24], hence the $\mathrm{pH}$ values obtained simply show that the papers vary as expected according to their preparation. Figure 2 shows the appearance of the swatches during aging. Figure 3 shows plots of color change, measured in units of $\Delta \mathrm{E}$, of aluminium- and tin-complexed cochineal and uncomplexed cochineal on paper supports with alkaline, neutral and acidic $\mathrm{pH}$ versus hours of exposure. On gelatin/alum sized paper (acidic) and on neutral paper the rates of fading of all the complexes are similarly fast; however, on alkaline paper the aluminium complex fades much more quickly than the tin complex, which fades faster than the uncomplexed carminic acid. We are ignoring the intermediate yellow product that can be produced on photooxidation of some anthraquinone pigments.

Figure 4 summarizes $\Delta \mathrm{E}$ after $70 \mathrm{~h}$ of aging for the uncomplexed and the aluminium- and tin-complexed paints. On alkaline paper, the aluminium lake, $\mathrm{CA}-\mathrm{Al}$, is the least photostable in comparison with both the uncomplexed colorant (CA) and the tin complex (CA-Sn). This relative rate of fading is the behavior most often cited. However, on acidic paper, the behavior is inverted, and $\mathrm{CA}-\mathrm{Al}$ is relatively the most stable. The tin-laked cochineal is less light stable in acidic or neutral conditions than at alkaline $\mathrm{pH}$. There are quite significant changes in relative reactivity over the $\mathrm{pH}$ range $4.2-7.8$ for individual colorants, CA being the most sensitive to $\mathrm{pH}$, but the color loss of the laked pigments also depends on $\mathrm{pH}$. 
a

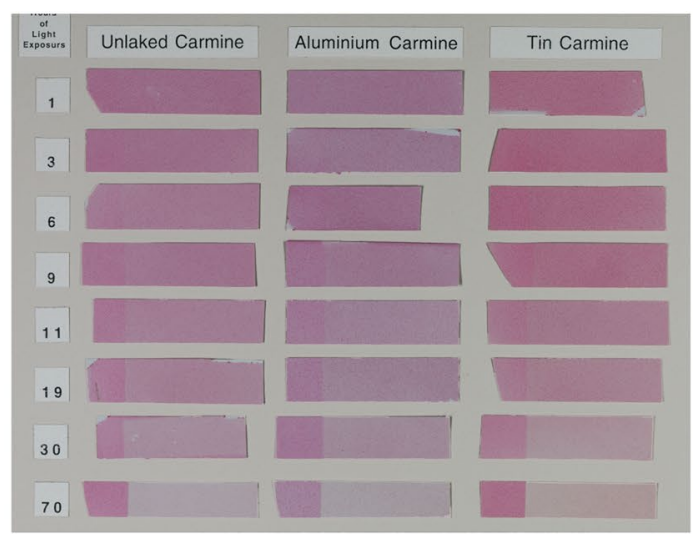

b

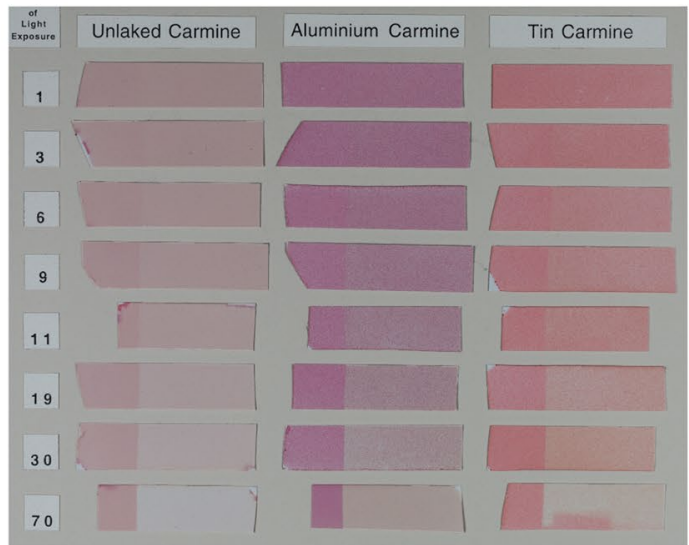

C

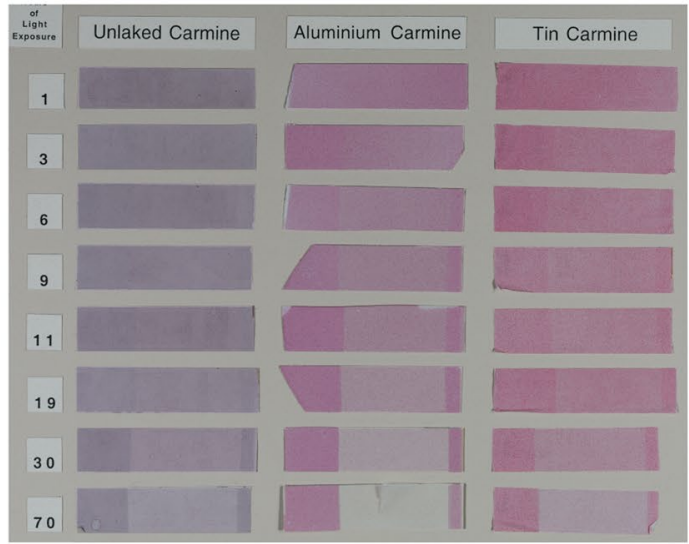

Fig. 2 Paper swatches with watercolor paints made using uncomplexed, Al-and Sn-complexed carminic acid during accelerated light fading (1-70 h). a On acidic paper. b On neutral paper. c On alkaline paper

\section{Discussion}

Cennini's observations regarding the relative stability of red lakes were likely made about the pigments prepared from lac or kermes, that contain laccaic acid (7-acetyl-6-ethyl-3,5,8-trihydroxy-9,10-dioxo-9,10-dihydro-1,2-anthracene dicarboxylic acid) or kermesic acid (3,5,6,8-tetrahydroxy-1-methyl-9,10-dioxo-9,10-dihydroanthracene-2-carboxylic acid), which are chemically related to carminic acid, the main component in the cochineal colors. These molecules are members of the chemical class of anthraquinones, as are alizarin, purpurin, and pseudopurpurin, which are among the molecules extracted from various roots and found in preparations of the colorant madder. Owing to their chemical similarity, in the following discussion we will assume that measurements of one member of the anthraquinone class are relevant, even if not completely similar, to understanding the chemistry of all members of the class.

The results presented here conform to Cennini's observation about red lakes prepared from alum-mordanted clothlets being less stable than those made directly from the unmordanted species. A similar observation had been made by Saunders and Kirby [25] who found that watercolors made using uncomplexed carminic acid were more stable than either the aluminium- or tin-complexed colorants. They found that the presence of $\mathrm{Ca}^{2+}$ in the formulation destabilized the aluminium complex. Analogous results have been observed for dyed fibers; for example, Gupta et al. [26] comparing the effect of various mordants and mordanting methods on the lightfastness of purpurin on nylon, found that while mordanting with copper or iron improved lightfastness, using aluminium, and to some extent tin, decreased the relative lightfastness of the dye compared to the unmordanted dye. Similar results were obtained for wool, and the procedures used for dyeing influence stability on wool as well as on nylon $[27,28]$. Alum and tin mordants for yellow dyes on wool gave the least stable colors [29]. Our experiments show that the situation is complex, and that the $\mathrm{pH}$ of a paper substrate contributes to the comparative instability of an anthraquinone dye or pigment in watercolor paint whether mordanted (i.e., complexed) or not.

Most studies of the chemistry of anthraquinones have been carried out in solution on uncomplexed species, though there has been work on a number of metalligand complexes in the solid state that were aimed to assist preservation studies and link to solution chemistry [30, 31]. Despite considerable research, the mechanisms and parameters affecting fading have not been fully elucidated, and in fact there are directly contradictory statements in the literature, as well as assertions that are not universally applicable, such as relationships between intensity of luminescence and photostability, and that deprotonated species are more light stable. These conflicting interpretations appear to be because a large number of factors contribute to change and loss of color of anthraquinone compounds, including $\mathrm{pH}$, the presence of reducing/oxidizing agents, the concentration of oxygen, the wavelength used for photochemical reactions, 

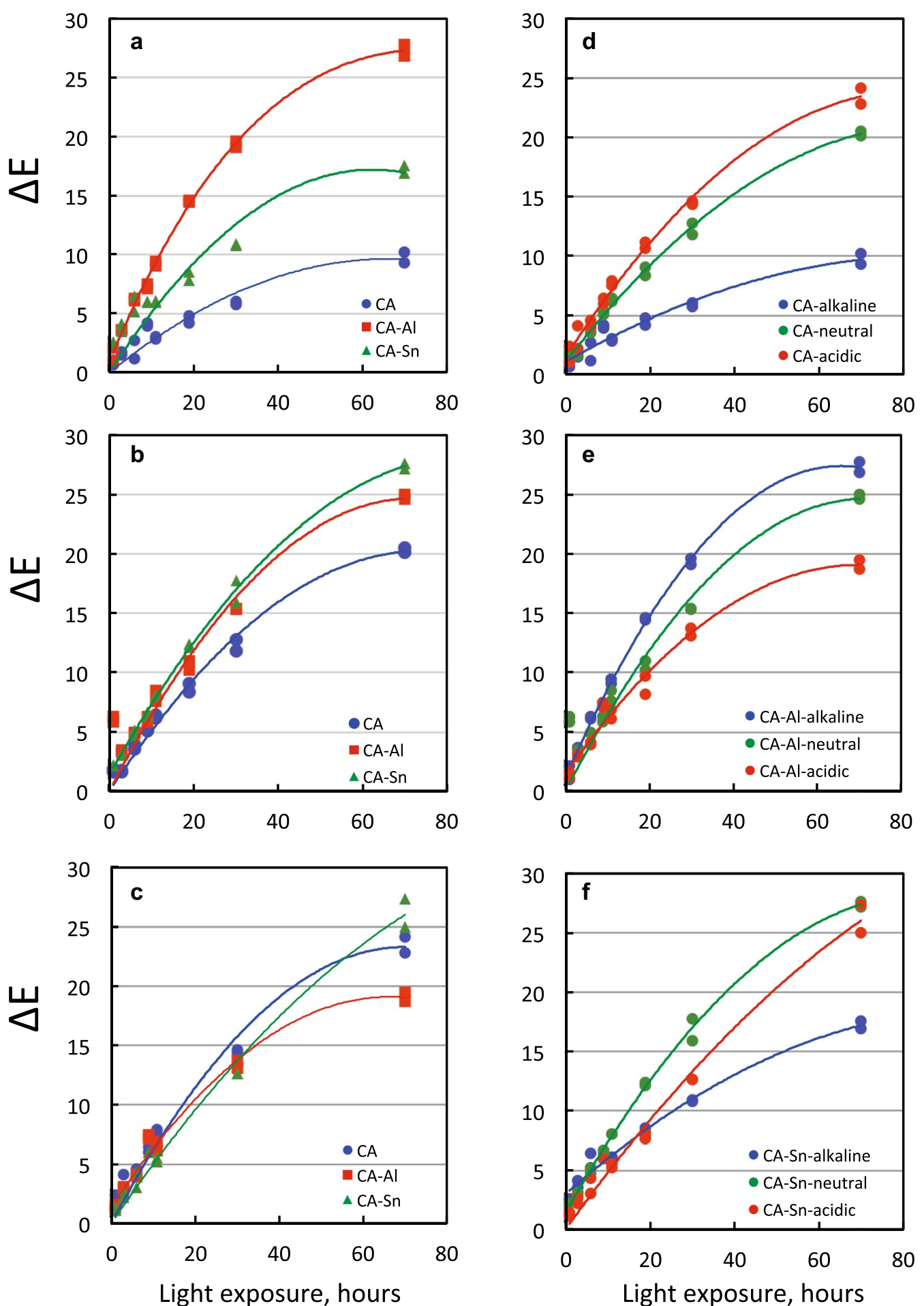

Fig. 3 Graphs of $\triangle E$ versus exposure time to light aging in a weatherometer. Arbitrary lines are drawn to aid visualizing the changes. a Three complexes on alkaline paper. b Three complexes on neutral paper. c Three complexes on acidic paper. $\mathbf{d}$ CA-Sn lake on three papers. e CA-Al lake on three papers. $\mathbf{f}$ Uncomplexed carmine, CA, on three papers 


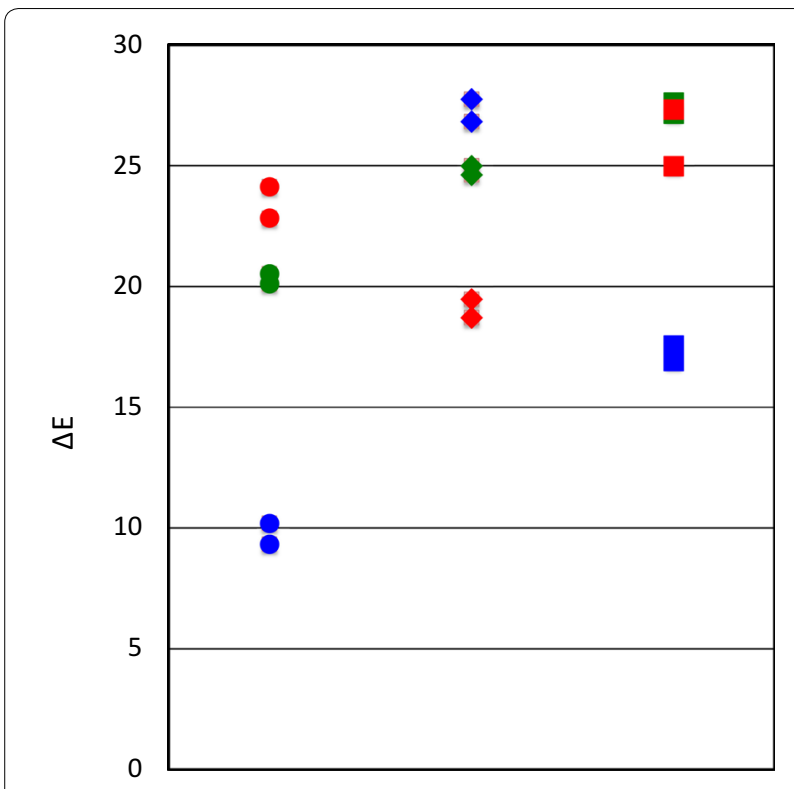

Fig. 4 Plot of $\Delta E$ measured for three cochineal-based pigments on different paper supports after $70 \mathrm{~h}$ of light exposure. Blue alkaline paper; green neutral paper; red acidic paper; circle uncomplexed colorant, CA; rhomb aluminium-laked pigment, CA-Al; square tin-laked pigment, $\mathrm{CA}-\mathrm{Sn}$

and in the condensed phase, $\mathrm{RH}$, among others. Control of all these parameters at once is difficult and rarely seen or achievable. It is also apparent that there are oxidative and non-oxidative pathways to colorless compounds, and both thermal and photochemical processes operate.

Photobleaching in solution has been attributed to the population of a tautomeric photoactive triplet state that reacts with oxygen. Figure 5 shows the Jablonski diagram proposed by Stapelfeldt et al. [32]. The diagram on the left is the state for the ligand with all the phenolic hydroxyl groups being protonated, and on the right the diagram for deprotonated species. For the fully protonated ligand species, the intersystem crossing (ISC) between the first lowest singlet state and the triplet state is symmetry forbidden. However, in the deprotonated species the relative energy of $S_{1}$ and $S_{2}$ is inverted, and ISC to a $T_{1}$ state that reacts with oxygen is symmetry allowed, leading to more oxidation of the species in alkaline solutions. This is not what we observed on paper. For alizarin and similar anthraquinones, in this excited state an internal enol-keto tautomerization with proton transfer from a hydroxyl group to the close-by keto group can occur decreasing the rate of population of the triplet state [33]. Bleaching reactions are promoted in proton-donating solvents. Recent studies have shown that a number of deactivation pathways can occur in anthraquinones, including emission from tautomeric states following excited state internal electron transfer and from population of a dark, non-radiative state that irreversibly leads to a colorless molecule $[34,35]$.

\section{Metal-complexed pigments}

Most anthraquinone pigments are made by complexing with metal ions, often $\mathrm{Al}^{3+}$, but also $\mathrm{Sn}(\mathrm{IV}), \mathrm{Ca}^{2+}$, and $\mathrm{Fe}(\mathrm{III})$, which imparts insolubility in a binding medium and also produces a variety of colors. For CA complexes, the UV-Vis spectra of most of these are similar, displaying a shift in energy up or down relative to the uncomplexed dye [36]. The structure of metal complexes of carminic acid and its cognates is not settled business. Most researchers consider that alizarin and purpurin form bis complexes, $\mathrm{ML}_{2}$, with bidentate bonding of the ligand through one keto group of the quinone structure and the adjacent hydroxyl group at position 1 but others have suggested that the first metal ion attaches through hydroxyl groups at positions 1 and 2 (Fig. 6). The formation constant of $\mathrm{Al}(\text { alizarin })_{2}^{1+}$ is high: For the water-soluble sulfonated derivative, Alizarin Red S, $\log _{10}$
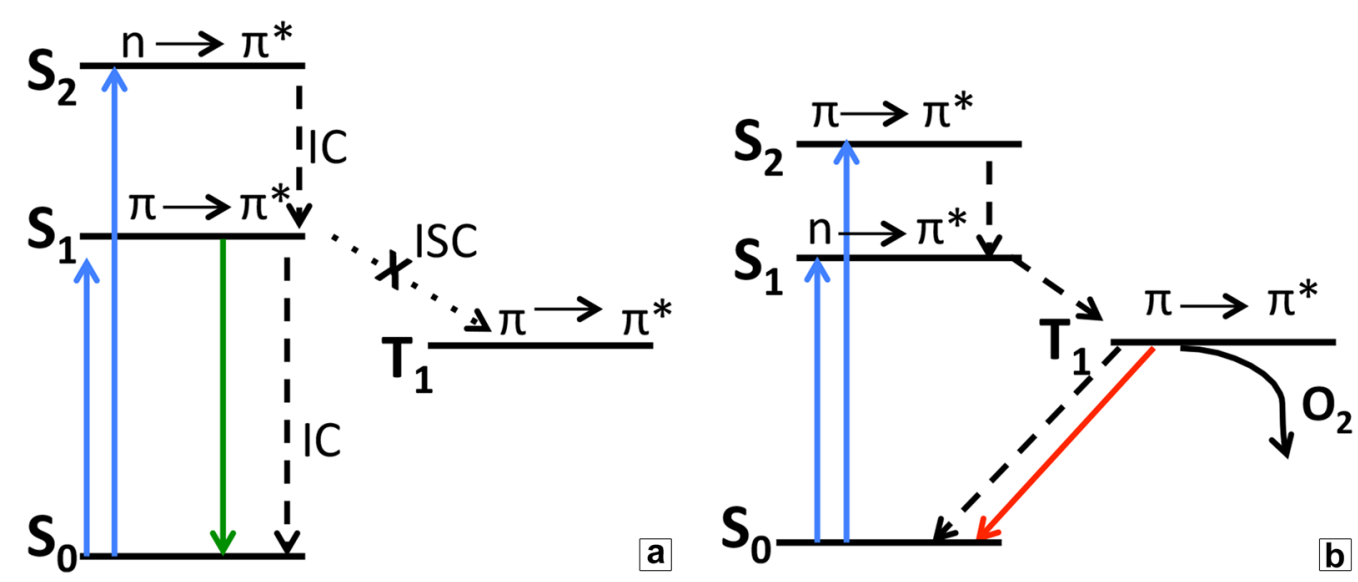

Fig. 5 Jablonski diagram for carminic acid in aqueous solution. a The fully protonated enol tautomer and $\mathbf{b}$ the keto tautomer (adapted from [32]) 


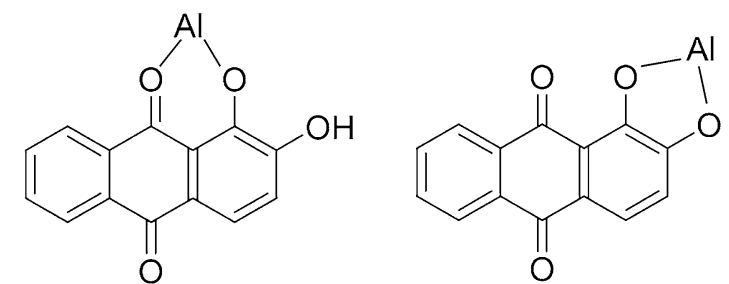

Fig. 6 Possible bonding modes for $\mathrm{Al}(\mathrm{III})$ and other metals in anthraquinones with multiple hydroxyl groups

$\beta=12.88$ [37]. The bonding mode for metal complexes of carminic acid has been proposed to be bidentate via the quinone structure, though for the anthraquinones, such as carminic or kermesic acid, bonding through the carboxylic acid group and an adjacent hydroxyl group has been suggested since $-\mathrm{COOH}$ is the most acidic group in the molecule. This is possible, but there is less advantage from electron delocalization in this configuration. For carminic acid, formation of $\mathrm{M}(\mathrm{CA})$ complexes, where $\mathrm{M}=\mathrm{Cu}(\mathrm{II}), \mathrm{Zn}(\mathrm{II}), \mathrm{Co}(\mathrm{II})$, or $\mathrm{Hg}(\mathrm{II})$, has a large $\log _{10} \beta$ and occurs over a wide $\mathrm{pH}$ range [38]. A tin complex of CA recrystallized from organic solvents was found to have seven-coordinate tin [39]. Structural variations likely exist in historical pigments since there are many ways to prepare them and the reactions are sensitive to $\mathrm{pH}$, the relative concentrations of reactants, and the addition of counter ions, etc. The variation among the formulae makes direct comparison among results difficult, and is part of the reason that there is not yet a consensus on why the metal complexes are more lightsensitive than the uncomplexed species. Ligation would appear to preclude the keto-enol transformation that promotes access to the triplet state, but internal conversion to deactivate the first excited singlet state may be enhanced in the metal complexes. However, on the nonbonding side of the ligand a keto-enol tautomerization analogous to that occurring in the uncomplexed species might occur in the ground and excited state [40]. The fluorescence spectra offer little evidence to suggest electronic differences among the various CA complexes [36]; however, fluorescence lifetime measurements might give insight into relative access to a photoactive triplet state. In the dark state, electron transfer may be favored to some extent in the metal-complexed species, which would account for the faster fading. Elucidation of these details might help understand the dependence of fading rates on so many parameters.

\section{Role of the binding medium}

As shown here and in other work, the chemical environment affects the stability of the cochineal pigments and dyes on objects. Anthraquinones have well-known antioxidant effects, even if they are not always potent [41]. Anthraquinone is used in the delignification of wood pulp for paper-making where its effect is thought to occur by electron transfer to a lignin molecule [42]. The antioxidant properties of anthraquinones are evident from the slow drying of oil paints that comprise red lakes. A few studies on the fading of this class of pigment in watercolor paints have been undertaken, and effects of the binding medium and the paper substrate on reactivity of the pigments have been observed [43, 44]. In a study of the madder watercolors, increased degradation of paper was noted when iron-containing madder paints were used [43] suggesting redox chemistry involving electron transfer; analogously, the paper support has been shown to be involved in photo-fading of the redox-active pigment Prussian blue [45]. These observations indicate more work will need to be done to investigate the activity of lake pigments in the presence of binders and supports to understand their mutual influence. The work reported here suggests that understanding the parameters that are the major influences on the stability of lakes in paint is complex, and determining how the redox chemistry of anthraquinones is affected by its environment, notably from this study the role of the $\mathrm{pH}$ of paper, requires further examination.

\section{Conclusion}

Chemical alteration that leads to changes in color needs to be distinguished from artists' intentional use of novel or atypical materials or mixtures. Our increasingly sophisticated methods for chemical analysis can be applied to understanding color use and unforeseen color change in artifacts. Knowing the original materials used in ancient color worlds gives us an understanding of their aesthetics, technology and trade routes, but our conclusions must be tempered through understanding unintentional change in chemistry and color.

For the red lake pigments on paper, color loss on exposure to light and its mitigation are the largest concern for conservation; however, increased sensitivity to light or color changes possibly occurring due to changing $\mathrm{pH}$ during treatments are also important to keep in mind. Empirical observations regarding stability are clearly limited: however, when dealing with comparatively slow reactions that can be documented visually in works of art, they offer insight into anticipating incipient change, and help focus experimental research onto fruitful paths along which interesting chemical processes that are associated with ongoing color change in art can be investigated. The factors involved are numerous, and the chemistry of the entire system that forms the artwork is implicated in change, as demonstrated in this work by the role of $\mathrm{pH}$ of the substrate on different forms of 
cochineal-based colorants. Anecdotal evidence from conservators and artists may help focus our work on the variables most important for preservation of cultural heritage.

\section{Authors' contributions}

$\mathrm{BHB}$ and YS conceived and designed the study. BHB prepared the lake pigments and wrote the paper. YS prepared the paper samples, the paint samples, undertook the aging studies, and performed the color measurements. The work was undertaken at NGA. Both authors read and approved the final manuscript.

\section{Author details}

1 Scientific Research Department, National Gallery of Art, 2000B South Club Drive, Landover, MD 20785, USA. ${ }^{2}$ US National Archives and Records Administration, Washington, DC, USA

\section{Acknowledgements}

We are grateful to Michael R. Palmer for assistance in the aging studies and Michelle Stein for photography of the paint sample swatches.

\section{Competing interests}

The authors declare that they have no competing interests.

\section{Publisher's Note}

Springer Nature remains neutral with regard to jurisdictional claims in published maps and institutional affiliations.

Received: 27 February 2017 Accepted: 25 May 2017

Published online: 26 July 2017

\section{References}

1. Cennini C. The Craftsman's Handbook 'Il Libro dell'Arte'. New York: Dover; 1954. p. 26.

2. Corbeil MC, Helwig K. An occurrence of pararealgar as an original or altered artists' pigment. Stud Conserv. 1995:40:133-8. doi:10.2307/1506513.

3. Monico L, Janssens K, Hendriks E, Vanmeert F, Snickt G, Cotte M, et al. Evidence for degradation of the chrome yellows in van Gogh's sunflowers: a study using noninvasive in situ methods and synchrotron radiation-based X-ray techniques. Ang Chem Int Edit. 2015. doi:10.1002/ anie. 201505840.

4. Aze S, Vallet JM, Detalle V, Grauby O, Baronnet A. Chromatic alterations of red lead pigments in artworks: a review. Phase Transit. 2008;81(2-3):14554. doi:10.1080/01411590701514326.

5. Zhao Y, Tang Y, Tong T, Sun Z, Yu Z, Zhu Y, et al. Red lead degradation: monitoring of color change over time. New J Chem. 2016;40(4):3686-92. doi:10.1039/C5NJ02426A.

6. Pouyet E, Cotte M, Fayard B, Salomé M, Meirer F, Mehta A, et al. 2D $X$-ray and FTIR micro-analysis of the degradation of cadmium yellow pigment in paintings of Henri Matisse. Appl Phys A. 2015;121(3):967-80. doi:10.1007/s00339-015-9239-4.

7. Spring M, Grout R. The blackening of vermilion: an analytical study of the process in paintings. Natl Gallery Tech Bull. 2002;23:50-61.

8. Keune K, Boon JJ. Analytical imaging studies clarifying the process of the darkening of vermilion in paintings. Anal Chem. 2005;77(15):4742-50. doi:10.1021/ac048158f.

9. Hogan C, Da Pieve F. Colour degradation of artworks: an ab initio approach to X-ray, electronic and optical spectroscopy analyses of vermilion photodarkening. J Anal At Spectrom. 2015;30(3):588-98. doi:10.1039/ C4JA00327F.

10. Noble P, van Loon A, Boon JJ. Chemical changes in old master paintings II: darkening due to increased transparency and metal soap formation. In: Verger I, editor. ICOM-CC 14th triennial meeting preprints. London: James and James; 2005. p. 496-503.
11. van den Berg KJ, Van Eikema Hommes MH, Groen KM, Boon JJ, Berrie BH. On copper green glazes in paintings. In: Goupy J, Mohen JP, editors. Art et chemie, la couleur. Paris: CNRS; 2000. p. 18-21.

12. Kühn H. Verdigris and copper resinate. In: Roy A, editor. Artists' pigments: a handbook of their history and characteristics. Washington, DC: National Gallery of Art and Archetype; 2012.

13. De la Roja JM, San Andrés M, Cubino NS, Santos-Gómez S. Variations in the colorimetric characteristics of verdigris pictorial films depending on the process used to produce the pigment and the type of binding agent used in applying it. Color Res Appl. 2007;32(5):414-23. doi:10.1002/ col.20311.

14. Brommelle NS. The Russell and Abney report on the action of light on water colours. Stud Conserv. 1964;9(4):140-52. doi:10.2307/1505213.

15. Beltran VL, Druzik J, Maekawa S. Large-scale assessment of lightinduced color change in air and anoxic environments. Stud Conserv. 2012:57(1):42-57.

16. Lerwill A, Townsend JH, Thomas J, Hackney S, Caspers C, Liang H. Photochemical colour change for traditional watercolour pigments in low oxygen levels. Stud Conserv. 2015;60(1):15-32

17. Cardon D. Natural dyes: sources, tradition, technology and science. London: Archetype; 2007

18. Schweppe H, Roosen-Runge H. Carmine. In: Feller RL, editor. Artists pigments: a handbook of their history and characteristics. Washington, DC: National Gallery of Art; 1986. p. 255-83.

19. Neri A. The art of glass. Sheffield: Society of Glass Technology; 2001. p. 408.

20. Church AH. The chemistry of paints and painting. London: Seeley and Co. Ltd.; 1890. p. 208.

21. Bersch J. The manufacture of mineral and lake pigments. London: Scott, Greenwood; 1901. p. 358-60.

22. Brückle I. The role of alum in historical papermaking. Abbey Newslett. 1993;17(4). http://cool.conservation-us.org/byorg/abbey/an/an17/ an17-4/an17-407.html.

23. Barrett T. 4.2 Conservation paper production. Pap Conserv. 1989;13(1):735. doi:10.1080/03094227.1989.9638372.

24. Joel A, Indictor N, Hanlan JF, Baer NS. The measurement and significance of $\mathrm{pH}$ in paper conservation. Bull Am Gr Int Inst Conserv Hist Artist Works. 1972:12(2):119-25. doi:10.2307/3179136.

25. Saunders D, Kirby J. Light-induced colour changes in red and yellow lake pigments. Natl Gallery Tech Bull. 1994;15:79-97.

26. Gupta D, Gulrajani ML, Kumari S. Light fastness of naturally occurring anthraquinone dyes on nylon. Coloration Technology. 2004;120(5):20512. doi:10.1111/j.1478-4408.2004.tb00119.x.

27. Manhita A, Ferreira V, Vargas H, Ribeiro I, Candeias A, Teixeira D, et al. Enlightening the influence of mordant, dyeing technique and photodegradation on the colour hue of textiles dyed with madder-a chromatographic and spectrometric approach. Microchem J. 2011;98(1):82-90. doi:10.1016/j.microc.2010.12.002.

28. Clementi C, Nowik W, Romani A, Cibin F, Favaro G. A spectrometric and chromatographic approach to the study of ageing of madder (Rubia tinctorum L) dyestuff on wool. Anal Chim Acta. 2007:596(1):46-54. doi:10.1016/j.aca.2007.05.036.

29. Crews PC. The influence of mordant on the lightfastness of yellow natural dyes. J Am Inst Conserv. 1982;21 (2):43-58.

30. Rader Bowers LM, Schmidtke Sobeck SJ. Impact of medium and ambient environment on the photodegradation of carmine in solution and paints. Dyes Pigm. 2016;127:18-24. doi:10.1016/j.dyepig.2015.12.012.

31. Grazia C, Clementi C, Miliani C, Romani A. Photophysical properties of alizarin and purpurin $\mathrm{Al}(\mathrm{III})$ complexes in solution and in solid state. Photochem Photobiol Sci. 2011:10(7):1249-54. doi:10.1039/C1PP05039G.

32. Stapelfeldt $H$, Jun $H$, Skibsted LH. Fluorescence properties of carminic acid in relation to aggregation, complex formation and oxygen activation in aqueous food models. Food Chem. 1993;48(1):1-11. doi:10.1016/0308-8146(93)90213-y.

33. Kunkely $\mathrm{H}$, Vogler A. Absorption and luminescence spectra of cochineal. Inorg Chem Commun. 2011;14(7):1153-5. doi:10.1016/j. inoche.2011.04.011.

34. Comini LR, Moran Vieyra FE, Mignone RA, Paez PL, Laura Mugas M, Konigheim BS, et al. Parietin: an efficient photo-screening pigment in vivo with good photosensitizing and photodynamic antibacterial 
effects in vitro. Photochem Photobiol Sci. 2017;16(2):201-10. doi:10.1039/ C6PP00334F.

35. Tan JA, Garakyaraghi S, Tagami KA, Frano KA, Crockett HM, Ogata AF, et al. Contributions from excited-state proton and electron transfer to the blinking and photobleaching dynamics of alizarin and purpurin. J Phys Chem C. 2017;121(1):97-106. doi:10.1021/acs.jpcc.6b09818.

36. Morales KM, Berrie BH. A note on characterization of the cochineal dyestuff on wool using microspectrophotometry. e-Preserv Sci. 2015;12:8-14.

37. Rowley DA, Cooper JC. Solution equilibria of alizarin red S with $\mathrm{Al}(\mathrm{III})$ and Ni(III). Inorg Chim Acta. 1988;147:257-9.

38. Atabey H, Sari H, Al-Obaidi FN. Protonation equilibria of carminic acid and stability constants of its complexes with some divalent metal ions in aqueous solution. J Sol Chem. 2012;41(5):793-803. doi:10.1007/ s10953-012-9830-7.

39. de Sousa AT, Bessler KE, Lemos SS, Ellena J, Gatto CC. Organotin complexes of alizarin and purpurin. Z Anorg Allg Chem. 2009;635(1):106-11. doi:10.1002/zaac.200800313.

40. Fain VY, Zaitsev BE, Ryabov MA. Tautomerism of metal complexes with carminic acid. Russ J Coord Chem. 2008;34(4):310-4. doi:10.1134/ s1070328408040118.
41. Ruifa J, Hongzheng B, Yin B, Xiuhua L. Theoretical study on the antioxidant activity of alizarin, purpurin, and pseudopurpurin. In: Limin Angela $L$, Dongqing W, Yixue L, editors. Interdisciplinary research and applications in bioinformatics, computational biology, and environmental sciences. Hershey: IGI Global; 2011. p. 130-40.

42. Hocking $\mathrm{M}$, Bolker $\mathrm{H}$, Fleming B. An investigation of anthraquinonecatalysed alkaline pulping via component modeling and electron spin resonance experiments. Can J Chem. 1980;58(18):1983-92. doi:10.1139/ v80-315.

43. Thomas J, Townsend JH, Hackney S, Strlič M. A chemiluminescence study of madder lakes on paper. Polym Degrad Stab. 2010;95(12):2343-9. doi:10.1016/j.polymdegradstab.2010.08.024.

44. Claro A, Melo MJ, Schäfer S, Seixas de Melo JS, Pina F, van den Berg KJ, et al. The use of microspectrofluorimetry for the characterization of lake pigments. Talanta. 2008;74:922-9. doi:10.1016/j.talanta.2007.07.036.

45. Gervais C, Languille M-A, Reguer S, Gillet M, Pelletier S, Garnier C, et al. Why does Prussian blue fade? Understanding the role(s) of the substrate. J Anal At Spectrom. 2013;28(10):1600-9. doi:10.1039/C3JA50025J.

\section{Submit your manuscript to a SpringerOpen ${ }^{\circ}$ journal and benefit from:}

- Convenient online submission

- Rigorous peer review

- Immediate publication on acceptance

- Open access: articles freely available online

- High visibility within the field

- Retaining the copyright to your article 